\title{
Preliminary tests of a damaged ship for CFD validation
}

\author{
Sungkyun Lee ${ }^{1}$, Ji-Myoung You ${ }^{2}$, Hyun-Ho Lee ${ }^{2}$, Taegu Lim ${ }^{1}$, Shin Hyung Rhee ${ }^{3}$ and Key-Pyo Rhee ${ }^{3}$ \\ ${ }^{I}$ Dept. of Naval Architecture and Ocean Engineering, Seoul National University, Seoul, Korea \\ ${ }^{2}$ Hyundai Maritime Research Institute, Hyundai Heavy Industries Co., Ltd., Ulsan, Korea \\ ${ }^{3}$ Dept. of Naval Architecture and Ocean Engineering, Research Institute of Marine Systems Engineering, \\ Seoul National University, Seoul, Korea
}

\begin{abstract}
One of the most critical issues in naval architecture these days is the operational safety. Among many factors to be considered for higher safety level requirements, the hull stability in intact and damaged conditions is the first to ensure for both commercial and military vessels. Unlike the intact stability cases, the assessment of the damaged ship stability is very complicated physical phenomena. Therefore it is widely acknowledged that computational fluid dynamics (CFD) methods are one of most feasible approaches. In order to develop better CFD methods for damaged ship stability assessment, it is essential to perform well-designed model tests and to build a database for CFD validation. In the present study, free roll decay tests in calm water with both intact and damaged ships were performed and six degree-of-freedom (6DOF) motion responses of intact ship in regular waves were measured. Through the free roll decay tests, the effects of the flooding water on the roll decay motion of a ship were investigated. Through the model tests in regular waves, the database that provides $6 D O F$ motion responses of intact ship was established.
\end{abstract}

KEY WORDS: Preliminary test; Damaged ship stability; CFD validation; Free roll decay test; 6DOF motion response.

\section{NOMENCLATURE}

A : Wave amplitude

$B_{44} \quad$ : Roll damping coefficient

$C_{44}$ : Roll restoring moment coefficient

$H \quad$ : Wave height

KB : The height above the keel for the center of buoyancy

KM : The height above the keel for the metacenter

$k_{x x} \quad$ : Roll radius of gyration

LCB : Longitudinal center of buoyancy

$L_{p p} \quad$ : Length between perpendiculars

$\lambda \quad$ : Wave length
$A_{44} \quad$ : Roll added moment of inertia

$B_{c r} \quad$ : Critical roll damping coefficient

GM : Metacentric height

$I_{44} \quad$ : Roll moment of inertia

KG : The height above the keel for the center of gravity

$k \quad$ : Wave number

$k_{y y} \quad$ : Pitch radius of gyration

LCG : Longitudinal center of gravity

$\Delta \quad$ : Displacement

\section{INTRODUCTION}

In these days, more non-conventional hull forms are being introduced for commercial and military vessels and international rules and regulations for the operational safety are becoming stricter with the increasing number of ROPAX and cruise ships.

Corresponding author: Shin Hyung Rhee

e-mail:shr@snu.ac.kr 
For these reasons, the interests about the damaged stability in seaway are gradually increasing. Unfortunately, it is very hard to assess the stability of a damaged ship because the motion of damaged ship is highly coupled with the flooding water behavior. When a ship is damaged, the ship motion is affected by the flooding water, and conversely, the flooding water motion is influenced by the ship motion. There are two general categories to investigate the damaged ship stability, model tests and numerical simulations. Nowadays, it is widely acknowledged that CFD methods are the only viable approach to deal with the coupled motion of a ship and flooding water because numerical simulation is more advantageous to tackle this complex problem efficiently and economically than the model tests.

Many research activities are being reported on the damaged ship stability. A lot of efforts were taken to simulate the motion of a damaged ship in numerical approaches. The roll motion of barge in regular waves was simulated in two dimensional (2D) domain (Chen, Liu, Chang and Huang, 2002) and the dynamic characteristics of the flooding water in the damaged compartment of a passenger ship were investigated (Cho, Hong and Kim, 2006). The flooding water motion in a damaged vessel's compartment was numerically simulated by using the volume of fluid (VOF) method (Gao, Vassalos and Gao, 2010). Lee, et al. (2012) numerically simulated the roll motion of barge and the flooding water behavior of the damaged compartment. There have been several attempts to investigate the damaged ship stability through the experimental study. The capsizing of damaged passenger ships in waves was investigated (Papanikolaou, et al., 2000), and model tests and simulations of a damaged frigate ship were conducted (Palazzi and Kat, 2004). Ruponen (2007) investigated about the progressive flooding problem of the damaged barge type passenger ship.

Although many researches on the damaged ship stability have been performed, there are more yet to be developed in CFD methods. In order to develop better CFD methods for damaged ship stability assessment, experimental database is essential for CFD validation. However, most experimental studies were only focused on reproducing exact same damaged condition not on the CFD validation. For a database to be valuable for CFD validation and development, the model tests should be designed to eliminate the unclear factors as many as possible. In this paper, a series of model tests were performed which is designed for the CFD validation. The free roll decay tests were performed in calm water with both intact and damaged conditions, and the 6DOF motion of the model was measured in regular waves with intact condition. The selected test hull form was a passenger ship provided by Ship Stability Research Center (SSRC) of the University of Strathclyde and the geometry of the damaged compartment was designed as simple as possible.

\section{MODEL DESCRIPTION}

\section{Model ship}

The model ship used in this paper was a passenger ship provided by SSRC. The length of the model is $3 \mathrm{~m}$ and the corresponding scale ratio is 82.57 . For the present study, the model tests were performed in the Seoul National University Towing Tank (SNUTT), which is $110 \mathrm{~m}$ long, $8 \mathrm{~m}$ wide, and $3.5 \mathrm{~m}$ deep. Table 1 shows the specification of the test model and Fig. 1 shows the profile of the model ship. The location of the center of gravity, the metacenter, and the mass moment of inertia were adjusted through the inclining test.

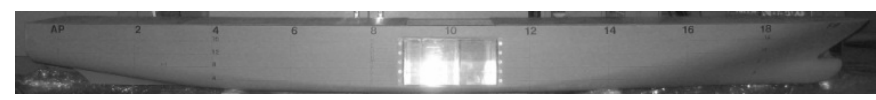

(a) Side view.

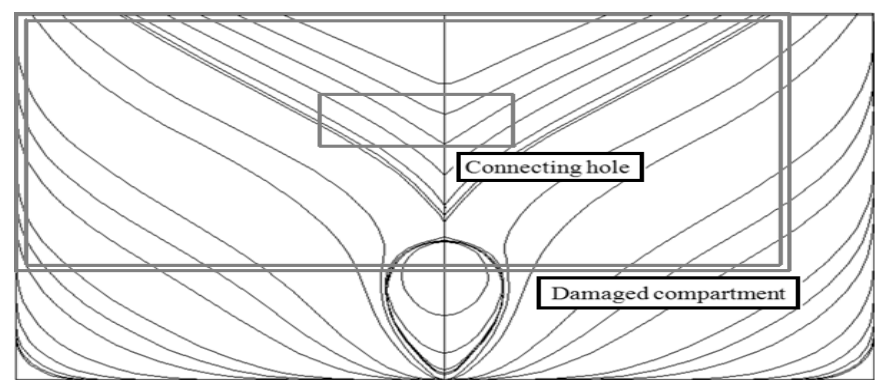

(b) Front view.

Fig. 1 Profile of the model ship. 
Table 1 Specification of the full scale and model.

\begin{tabular}{|l|c|c|}
\hline \multicolumn{1}{|c|}{ Term } & Full scale & Model \\
\hline$L_{p p}(m)$ & 247.7 & 0.43 \\
\hline Beam $(m)$ & 35.5 & 0.1 \\
\hline Draft $(m)$ & 8.3 & 0.1 \\
\hline Displacement (ton) & 56541.5 & -0.037 \\
\hline LCB $(m)$ (aft. from the midship) & -3.096 & -0.077 \\
\hline LCG $(m)$ (aft. from the midship) & -6.329 & 0.049 \\
\hline KB $(m)$ & 4.085 & 0.227 \\
\hline KM $(m)$ & 18.781 & 0.199 \\
\hline KG $(m)$ & 16.393 & 0.029 \\
\hline GM $(m)$ & 2.388 & 0.179 \\
\hline$k_{x x}(m)$ & 14.814 & 0.750 \\
\hline$k_{y y}(m)$ & 61.925 & \\
\hline
\end{tabular}

\section{Damaged compartment}

The damage location is at the midship and it was installed asymmetrically in the transverse direction (see Fig. 1(b)). The geometry of the damaged compartment was determined from the results of preliminary CFD calculation (Lee, et al., 2012). Fig. 2 shows the geometry of the damaged compartment. Damaged compartment has two compartments (one after the other) in the longitudinal direction connected through a small hole, so that there is a cross-flooding between the compartments. The longitudinal coordinates of the compartments in full scale are shown in Table 2. There is a damage hole on the starboard side of the compartment so that the flooding water rushes into the ship through the damage hole. Five wave probes were installed in the compartment to measure the free surface of the flooding water.

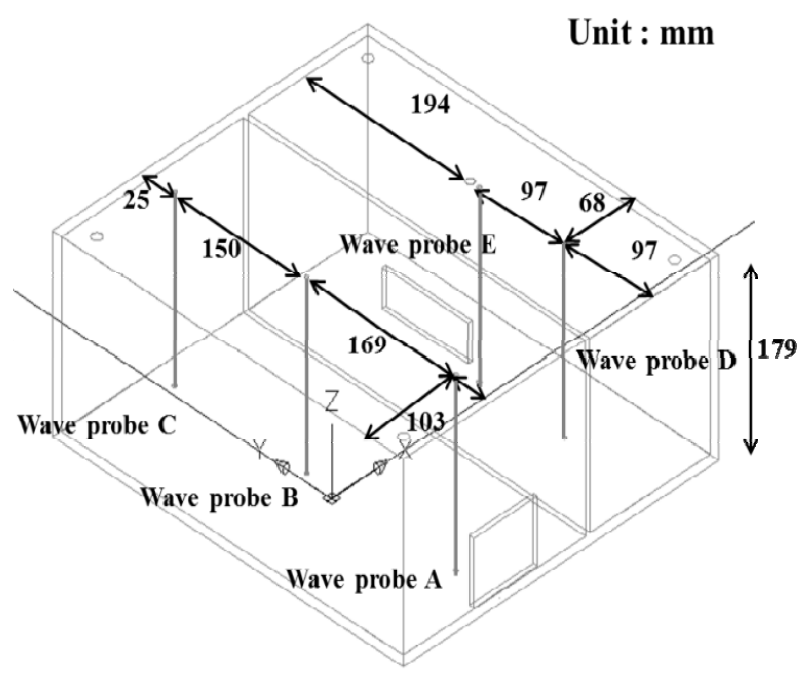

(a) Specification of compartment.

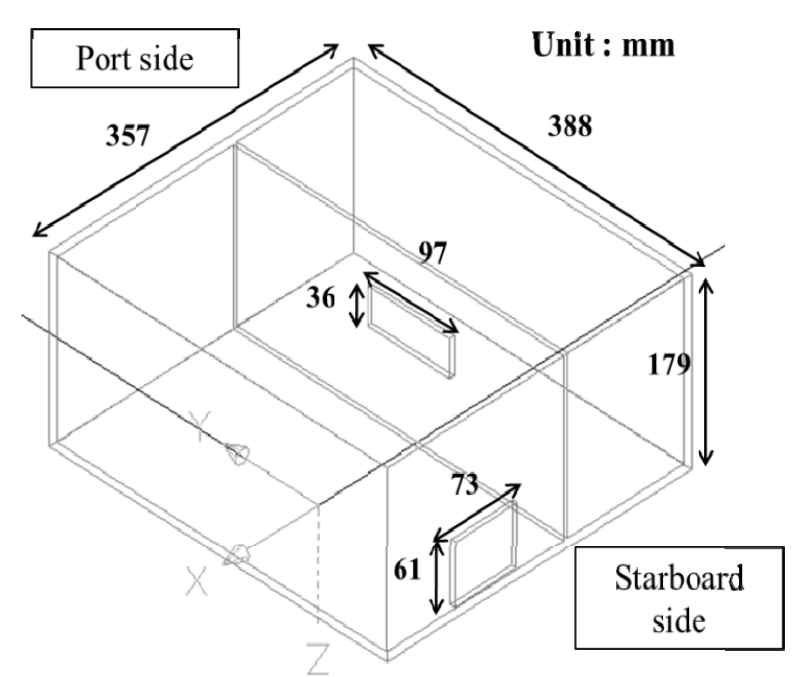

(b) Specification of connecting hole and damage hole.

Fig. 2 Geometry of the compartment. 
Table 2 The longitudinal coordinates of compartments.

\begin{tabular}{|c|c|c|}
\hline Compartment & $\mathrm{X} 1(\mathrm{~m})$ & $\mathrm{X} 2(\mathrm{~m})$ \\
\hline Fore section (from midship) & 6.687 & 17.750 \\
\hline Rear section (from midship) & -10.750 & 6.274 \\
\hline
\end{tabular}

\section{Measurement system}

In this paper, two measurement systems were used: ship motion measurement system and flooding water behavior measurement system. Firstly, the motion responses were measured with a combination of the accelerometers and inertial measurement unit (IMU). The IMU was mainly used for the roll motion measurement in the free roll decay test. The accelerometers were used to obtain 6DOF motion responses from the tests results in regular waves. Seven accelerometers located at the center of gravity (one), bow (two), stern (two), port (one), and starboard (one) of the model. From the measured accelerations, the 6DOF motion responses of the model were obtained using the strapdown method, suggested by Miles (1992). Fig. 3 shows the motion measurement system. Secondly, the height of the flooding water was measured by five capacitance type wave probes.

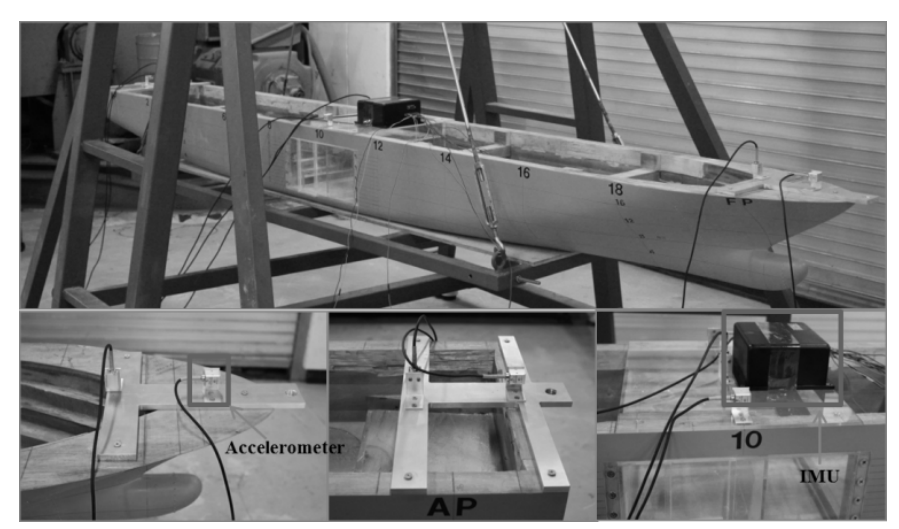

Fig. 3 Motion measurement system (IMU \& accelerometers).

\section{Opening mechanism}

To reproducing the damaged condition in the model test, opening mechanism was designed. In the damaged condition the measurement started with opening the gate. The opening time can also influence the overall flooding procedure, so the opening time should be clearly described. In this paper, the gate was opened using an air cylinder that pulled up the gate in the vertical direction. This mechanism was very simple and effective to achieve rapid acceleration. The opening time was approximately 0.09 second in model scale and it was confirmed that the induced roll motion due to the opening mechanism was negligible because the induced roll moment was very small compared to roll inertia of the model ship.

\section{FREE ROLL DECAY TESTS}

\section{Free roll decay in intact condition}

In intact condition, the model was initially inclined with an angle of 21 degrees and then released then the roll angle of the model was measured. To obtain accurate roll damping values, linear-plus-cubic model was used and linear-plus-cubic model can be expressed as Eq. (1).

$$
\left(I_{44}+A_{44}\right) \ddot{\phi}+B_{44,1} \dot{\phi}+B_{44,3} \dot{\phi}^{3}+C_{44} \phi=0
$$


The obtained roll damping was quantified with the damping ratio between the equivalent roll damping and critical roll damping of a ship. The meaning of the critical roll damping is the roll damping magnitude which makes the system critically damped one and it can be written as Eq. (2).

$$
B_{c r}=2 \sqrt{\left(I_{44}+A_{44}\right) \Delta \overline{G M}}
$$

Fig. 4 shows the comparison of the time histories of roll motion from the experimental data and the reproduced results. It could be known that the reproduced roll motion shows good agreement with the measured roll motion. Table 3 shows roll damping ratio and the roll period in intact condition.

Table 3 Test results of free roll decay test in intact condition.

\begin{tabular}{|c|c|}
\hline & Initial heel angle $\left(21^{\circ}\right)$ \\
\hline Roll periods & 2.05 seconds \\
\hline$B_{44} / B_{c r}$ & $2.46 \%$ \\
\hline
\end{tabular}

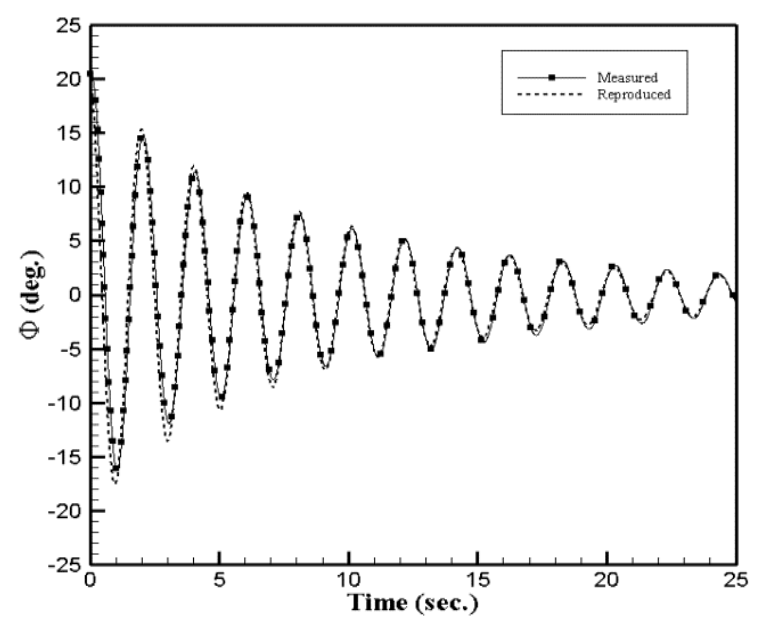

Fig. 4 Roll time history in intact condition.

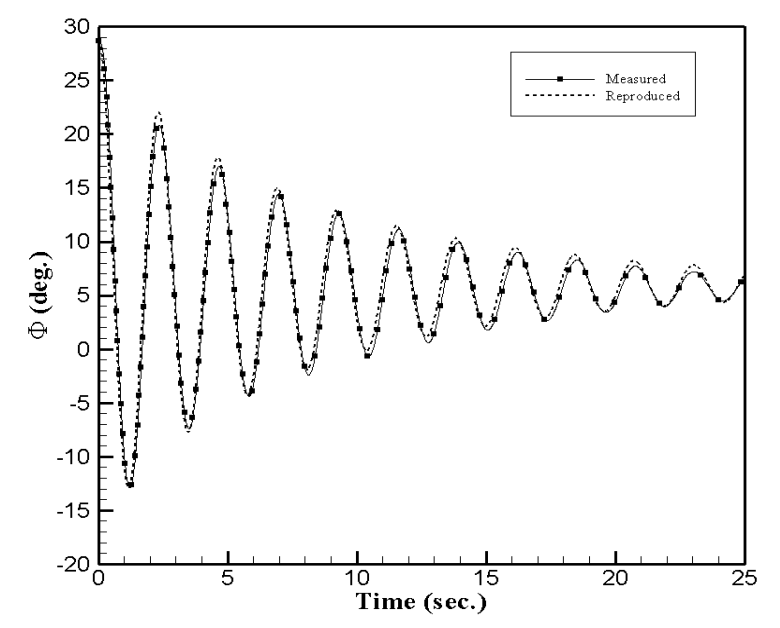

Fig. 5 Roll time history in damaged condition (First case).

\section{Free roll decay in damaged condition}

The free roll decay tests were performed with two different ways in damaged condition. In the first case, the test model was initially inclined with the gate opened until the flooding water is fully filled in the damaged compartment. Then the test model was released and the initial heel angle was 29 degrees to starboard side. When the ship was inclined, the flooding water flowed into the damaged compartment and there was overflow into the other section through the connecting hole. The roll damping value of the model was obtained to study the effect of the flooding water on the roll decay behavior of the ship. Fig. 5 shows the comparison between the measured roll motion and the reproduced results.

Fig. 6 shows the free surface elevation in the damaged compartment. The model heeled to the starboard side by an angle of 5.6 degrees after the decay motion was finished, because there was a shift of the center of gravity of the model due to the asymmetrical installation of the compartment in transverse direction. The mass of flooding water was calculated by using the measured free surface elevation of the compartment. In the fore section of the damaged compartment, the free surface elevation was measured with two wave probes and the mass of flooding water was approximately $4.04 \mathrm{~kg}$. In the rear section, the free surface elevation was measure with three wave probes and the mass of flooding water was approximately $5.85 \mathrm{~kg}$. In Fig. 5 , the roll decay period in damaged condition was shorter than that in intact condition and the amplitude of roll motion decreased more rapidly in damaged condition. These suggest that the flow in the damaged compartment might have played the role of anti-rolling tank, interfering the roll motion. Table 4 shows roll damping ratio and the roll period in first case. As shown in 
Table 4, it could be known that the roll damping is significantly increased when the ship is damaged. The flooding water imposed a significant influence on the roll motion of the ship in terms of the roll period and the damping ratio of roll amplitude. The roll period in damaged condition was longer than in intact condition to $10 \%$. Lee, et al. (2012) investigated the change of $\overline{G M}$ values by inclining test when the ship was damaged and it is confirmed that $\overline{G M}$ was decreased in damaged condition. The reduction of $\overline{G M}$ might be one of the main reasons for the increase of the roll period because the roll period is affected by the $\overline{G M}$ value as Eq. (3). Table 5 shows the $\overline{G M}$ values of the model ship in the intact and damaged condition.

$$
T=2 \pi \sqrt{\frac{I_{44}+A_{44}}{\Delta \overline{G M}}}
$$

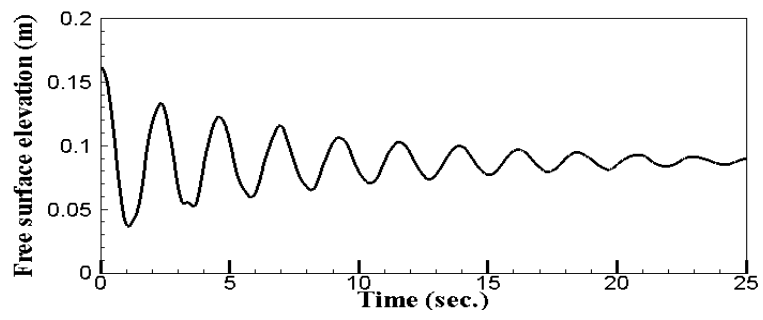

(a) Wave probe A.

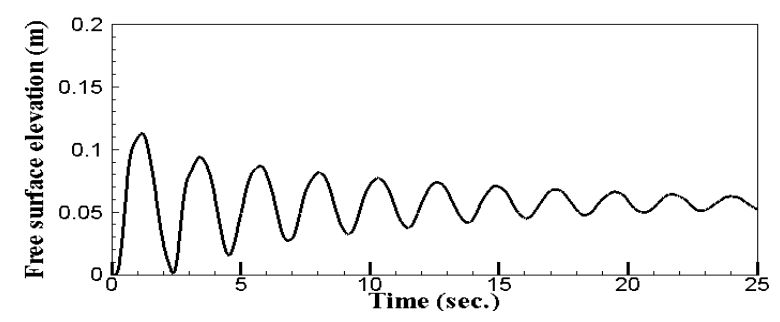

(c) Wave probe $\mathrm{C}$.

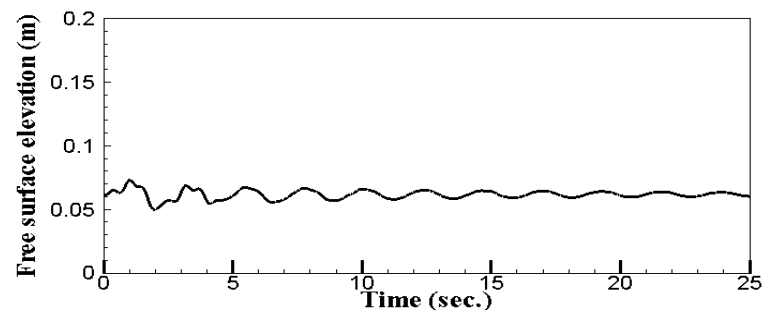

(b) Wave probe B.

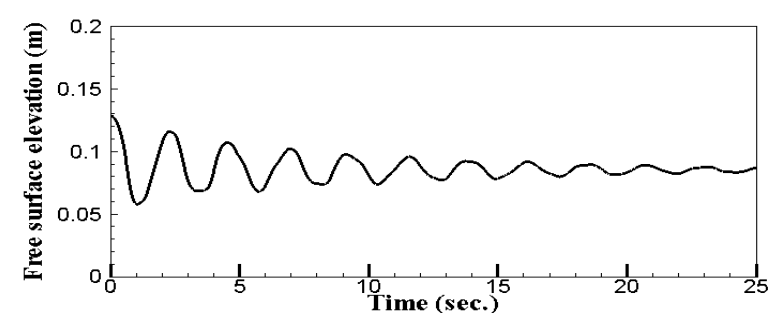

(d) Wave probe D.

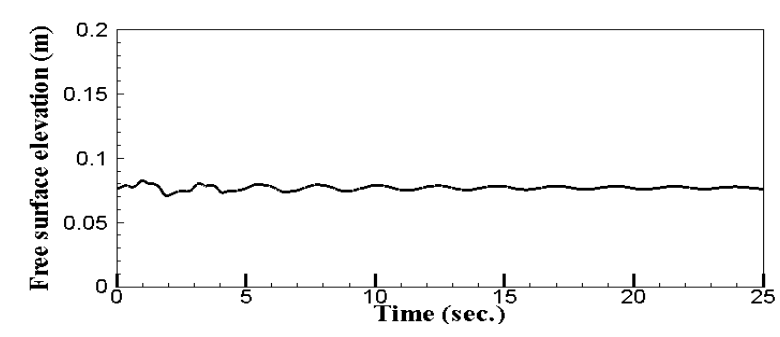

(e) Wave probe E.

Fig. 6 Free surface behavior in damaged compartment (First case).

Table 4 Roll period and damping value in damaged condition.

\begin{tabular}{|c|c|c|}
\hline & Intact & Damaged \\
\hline Roll periods & 2.05 & 2.27 \\
\hline$B_{44} / B_{c r}$ & $2.46 \%$ & $3.04 \%$ \\
\hline
\end{tabular}

Table 5 Roll period and damping value in damaged condition.

\begin{tabular}{|c|c|c|}
\hline & Intact & Damaged \\
\hline$\overline{G M}$ & $2.89 \mathrm{~cm}$ & $1.65 \mathrm{~cm}$ \\
\hline
\end{tabular}


In the second case, the test condition is designed to investigate the transient behavior of the damaged ship caused by flooding water. The test model was initially inclined with the gate closed. The initial heel angle was 24 degrees to starboard side and the test model was released with the gate opened. The reason why the free roll decay tests are conducted in the second case is as follows. When CFD methods are used to simulate the motion of the damaged ship, it is very difficult to calculate the behavior of the damaged ship, especially right after the ship is damaged. It is because the flooding water rushed into the damaged compartment abruptly and this flooding water will generate impact on the ship. The measured time history of the roll motion and the flooding behavior could be fully utilized for the CFD validation. Fig. 7 shows the measured roll motion of the model and Fig. 8 shows the free surface elevation in the damaged compartment. As shown in Fig. 8, there was no crossflooding through the connecting hole between compartments when the initial heel angle was 24 degree. It is because the vertical location of the connecting hole was higher than the free surface. Therefore only the fore section of the damaged compartment was filled by flooding water.

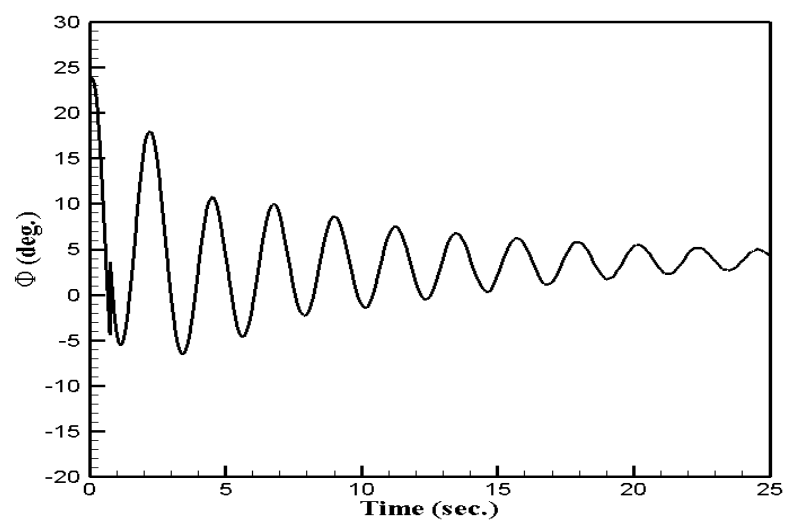

Fig. 7 Roll time history in damaged condition (Second case).

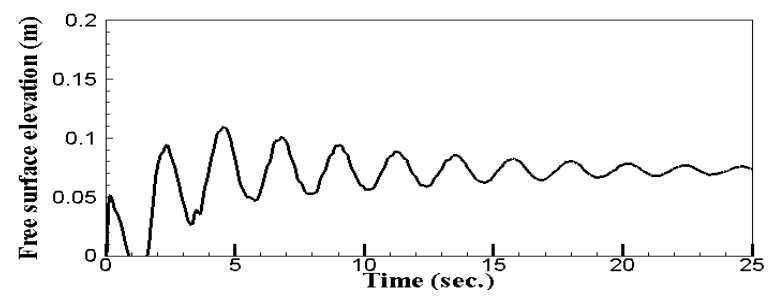

(a) Wave probe A.

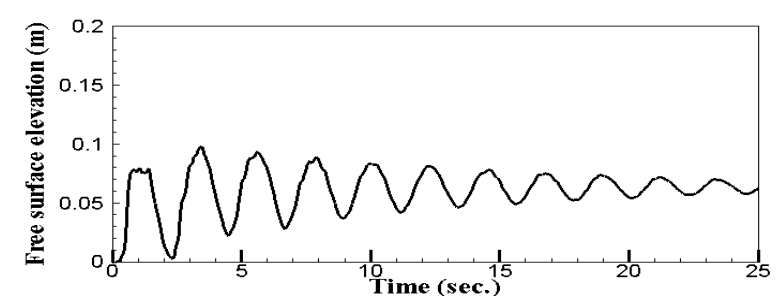

(c) Wave probe $\mathrm{C}$.

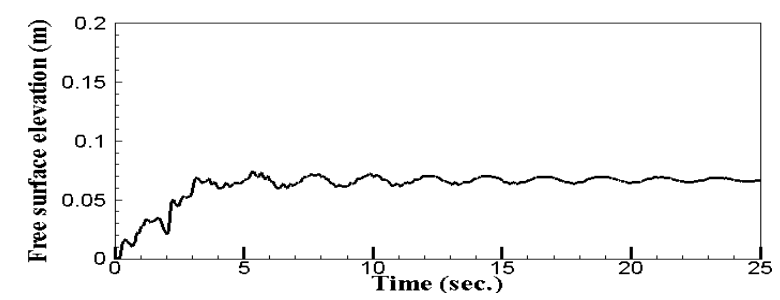

(b) Wave probe B.

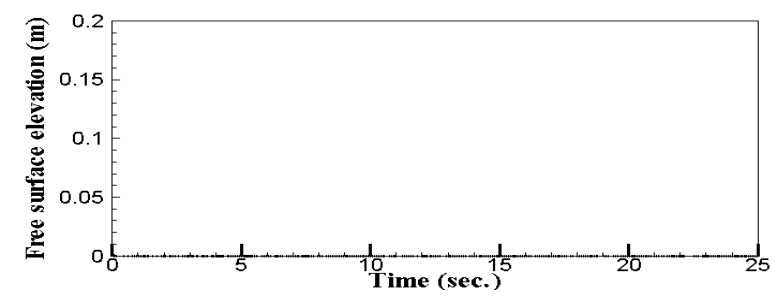

(d) Wave probe $\mathrm{D}$.

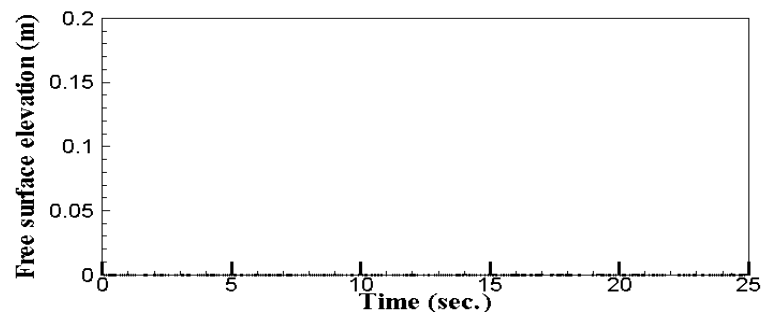

(e) Wave probe E.

Fig. 8 Free surface behavior in damaged compartment (Second case). 


\section{DOF MOTION RESPONSES IN REGULAR WAVES}

\section{Model experiments}

For the damaged ship, the full 6DOF motion responses should be considered, because the symmetry of the ship's motion has been already lost due to the damages. Moreover, because less degrees of freedom mean restrained motion and do not provide meaningful information on the damaged ship's motion, greater interest is in full 6DOF motion. In this paper, the model tests were performed only with the intact ship and the additional model tests with the damaged ship are planned to be conducted in the near future. For these reasons, 6DOF motion responses of intact ship were measured for the comparison with the test results of the damaged ship.

Model tests were carried out in beam waves for two wave slopes and five wave frequencies. Table 6 shows the test conditions in regular beam waves. To prevent the drift of the model ship, the mooring system was designed by using soft spring. This mooring system should not affect on the harmonic motion of the model ship while it should prevent the drift motion. Because motion period of the model ship does not exceed 20 seconds, spring constant is determined to get 100 seconds of motion period. Unlike the intact stability cases, the forward speed of a ship is of no or little interest in the damaged stability cases, because a ship hardly moves around when damaged. Fig. 9 shows the time history of the roll motion in Case 7. In Case 7, the exciting wave frequency is the resonance frequency of the roll motion so the amplitude of the roll motion became maximum.

Table 6 Wave conditions in regular waves.

\begin{tabular}{|c|c|c|c|}
\hline & Period (sec.) & Amplitude $(\mathrm{mm})$ & Wave slope $(H / \lambda)$ \\
\hline Case 1 & 1 & 13.01 & $1 / 60$ \\
\hline Case 2 & 1 & 7.81 & $1 / 60$ \\
\hline Case 3 & 1.5 & 29.27 & $1 / 100$ \\
\hline Case 4 & 1.5 & 17.56 & $1 / 60$ \\
\hline Case 5 & 1.96 & 29.84 & $1 / 100$ \\
\hline Case 6 & 1.96 & 54.95 & $1 / 100$ \\
\hline Case 7 & 2.06 & 32.97 & $1 / 60$ \\
\hline Case 8 & 2.06 & 60.42 & $1 / 100$ \\
\hline Case 9 & 2.16 & 36.25 & \\
\hline Case 10 & 2.16 & & \\
\hline
\end{tabular}

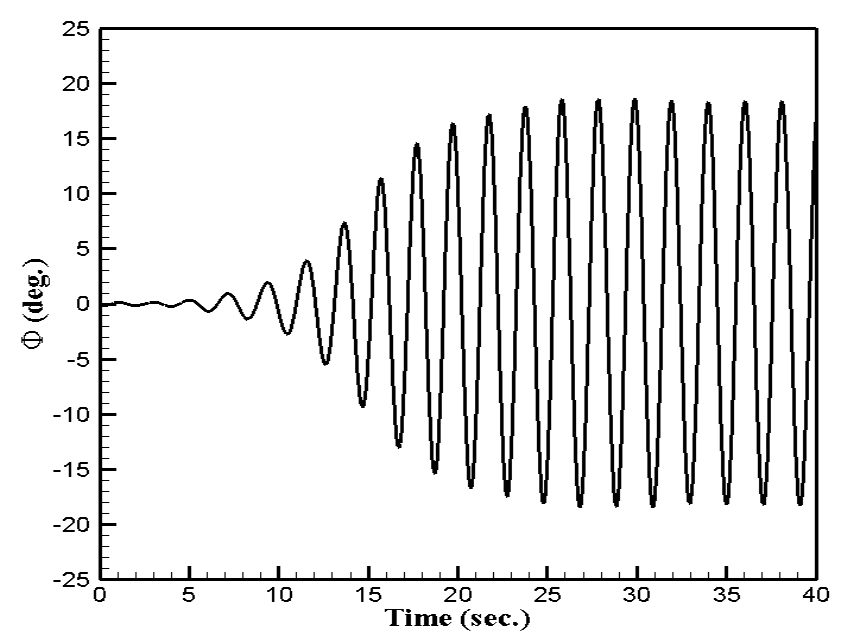

Fig. 9 Time history of roll motion in regular waves (Case 7). 


\section{Experimental results}

From the time histories of the motion responses in time domain, the motion responses in frequency domain were obtained by using Fast Fourier Transform (FFT). The motions responses of the model were also obtained by using the 3D boundary elements method because the motion response of the intact ship could be reliably obtained from the potential theory. Then the experimental results were compared with the results obtained from the potential theory.

As expected, 3DOF motions were mainly caused by beam waves such as sway, heave and roll motion. Fig. 10 shows the comparison of nondimensionalized motion responses between the present experiment and the computation based on the potential theory in frequency domain. In Fig. 10, different symbols were used to identify two groups of tests conducted with different wave slopes. In general, the agreement of the roll motion responses were very fair while the sway and heave motion responses did not have same degree of agreement as the roll motion, but overall trend was acceptable. In sway and heave motion, the nondimensionalized motion responses became smaller as the wave slope of incident waves became steeper. Especially, very large sway and roll motion responses were observed in the Case 1. These nonlinear phenomena can be called the parametric roll and it occurs if the transverse stability of ship varied twice during on natural roll period. Meanwhile, the occurrence of parametric roll was not observed in Case 2, even though the Case 2 has same wave frequency with that of Case 1, but has different wave slope.

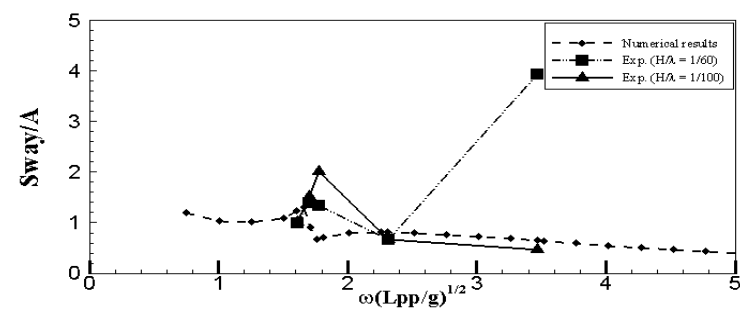

(a) Sway motion.

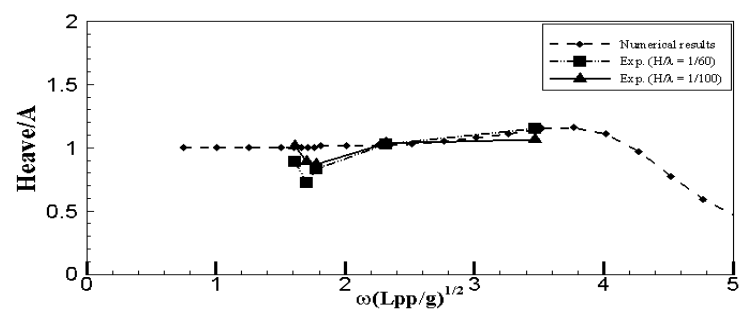

(b) Heave motion.

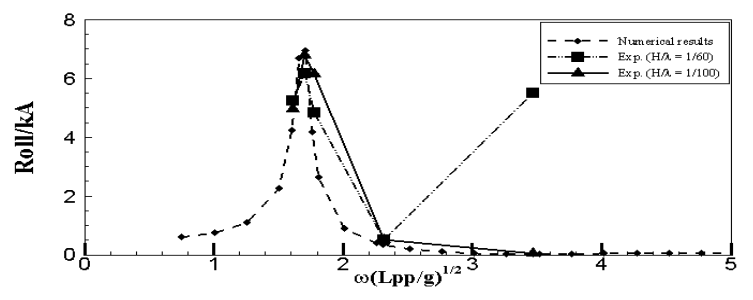

(c) Roll motion.

Fig. 10 Motion responses in frequency domain.

In the present study, parametric rolling of the ship was caused by the variation of the stability (as indicated by $\overline{G M}$ ) as the wave crests travel along the hull in transverse direction. In fact, parametric rolling of ships has continuously received wide attention of researchers and designers, since it is a relevant instabilizing mechanism. Paulling and Rosenberg (1959) mentioned that it is observed that ships have unwanted roll characteristics if the natural frequencies in heave and roll are in the ratio of 2:1 in beam waves and they produced parametric rolling by nonlinear coupling from heave motion theoretically and experimentally. Nowadays, the parametric rolling of ships has been of great interest in head waves since modern commercial ships have become larger so that the ship designs feature wide beam and large bow flares. Kim and Kim (2011) considered multi-level approach for the analysis of parametric roll phenomena with three kinds of computation methods: GM variation, impulse response function, and Rankine panel method. Kim, et al. (2011) developed a computer program which is based on a time-domain Rankine panel method for practical use to linear and nonlinear ship motion such as parametric rolling and structural loads in waves.

From the model tests in regular beam waves, the 6DOF motion responses were measured and it will be fully utilized for the validation of the CFD methods to simulate the damaged ship's motion in waves. During the model tests unexpected parametric rolling phenomena which is physically meaningful was occurred and this phenomena was not captured by the computation method based on the potential theory. To capture parametric rolling of ships with potential methods or CFD methods, the variation of the GM value should be exactly predicted. 


\section{CONCLUSIONS}

In the present study, a series of model tests were performed to build reliable database for the damaged ship's stability. Measured time histories of ship motion and flooding behavior were organized as a database for CFD validation.

Firstly, free roll decay tests were performed in intact and damaged condition to investigate the interaction between the roll motion of a ship and the flooding water. The damping coefficient of the model became large when the ship was damaged. The amplitude of roll motion decreased more rapidly in damaged because the flooding water might act like an anti-rolling tank.

Secondly, the full 6DOF motion responses of intact ship were measured in beam waves. Mooring system was design to prevent the drift motion of the model. In Case 7, the exciting wave frequency is the resonance frequency of the roll motion so the amplitude of the roll motion became maximum. Unexpected parametric rolling phenomena were occurred in Case 1 while these phenomena weren't observed in Case 2 which were same wave frequency but different wave slope.

\section{ACKNOWLEDGEMENTS}

The present study is supported by the Office of Naval Research (ONR) under the supervision of Dr. L.P. Purtell, the National Research Foundation of Korea (Grant No. 2010-0022835) and Multi-Phenomena CFD Research Center (Grant No. 20090093103) funded by the Ministry of Education, Science and Technology of the Korea government.

\section{REFERENCES}

Chen, H.C., Liu, T., Chang, K.A. and Huang, E.T., 2002. Time-domain simulation of barge capsizing by a Chimera domain decomposition approach. In: Proceedings of the $12^{\text {th }}$ International Offshore and Polar Engineering Conference, Kitakyushu, Japan, pp.314-321.

Cho, S., Hong, S. and Kim, Y., 2006. Investigation of dynamic characteristics of the flooding water of the damaged compartment of an ITTC RoRo-Passenger. Journal of the Society of Naval Architects of Korea, 43(4), pp.451-459 (in Korean).

Gao, Z., Vassalos, D. and Gao, Q., 2010. Numerical simulation of water flooding into a damaged vessel's compartment by the Volume of Fluid method. Ocean Engineering, 37(16), pp.1428-1442.

Kim, T. and Kim, Y., 2011. Multi-level approach for parametric roll analysis. International Journal of Naval Architecture and Ocean Engineering, 3(1), pp.53-64.

Kim, Y., Kim, K., Kim, J., Kim, T., Seo, M. and Kim, Y., 2011. Time-domain analysis of nonlinear motion responses and structural loads on ships and offshore structures : development of WISH programs. International Journal of Naval Architecture and Ocean Engineering, 3(1), pp.37-52.

Lee, S., You, J., Lee, H., Rhee, S.H. and Rhee, K., 2012. Experimental study on free roll decay motions of a damaged ship for CFD validation database. Journal of Society of Naval Architects of Korea, 49(1), pp.52-59 (in Korean).

Miles, M.D., 1992. Measurement of six degree of motions using Strapdown accelerometers. Hydraulic Laboratory, National Research Council, Ottawa, Canada.

Palazzi, L. and Kat, J., 2004. Model experiments and simulations of a damaged ship with air flow taken into account. $M a-$ rine Technology, 41(1), pp.38-44.

Papanikolaou, D., Zaraphonitis, G., Spanos, D., Boulougouris, E. and Eliopoulou, E., 2000. Investigation into the Capsizing of damaged RO-RO passenger ships in waves. In: Proceedings of $7^{\text {th }}$ International Conference on Stability of Ship and Ocean Vehicles, Tasmania, Australia.

Paulling, J.R. and Rosenberg, R.M., 1959. On unstable ship motions resulting from non-linear coupling. Journal of Ship Research, 3(1), pp.36-46.

Ruponen, P., 2007. Progressive flooding of a damaged passenger ship. Ph.D. Department of Mechanical Engineering, Helsinki University of Technology, Finland. 